\title{
Cash transfer and female labor supply: evidence from Brazil's rural area
}

\author{
Transferência de renda e oferta de trabalho feminino: evidências da \\ área rural do Brasil \\ Fulvia Fernanda Lima ${ }^{1}$, Gisléia Benini Duarte ${ }^{1}$ (D)
}

1Pró-reitora de Pesquisa e Pós-graduação, Programa de Pós-graduação em Administração e Desenvolvimento Rural, Universidade Federal Rural de Pernambuco (UFRPE), Recife (PE), Brasil. E-mail: fulvia_fernanda@hotmail.com; gisleiaduarte@gmail.com

How to cite: Lima, F. F., \& Duarte, G. B. (2021). Cash transfer and female labor supply: evidence from Brazil's rural area. Revista de Economia e Sociologia Rural, 59(4), e217424. https://doi.org/10.1590/1806-9479.2021.217424

\begin{abstract}
This paper analyzed the relationship between Bolsa Familia Program (BFP) and labor supply of women in rural areas from Brazil, using the Propensity Score Matching (with the nearest-neighbor, kernel, and IPW criteria), Ordinary Least Squares on the treatment (beneficiaries), and control (non-beneficiaries) groups with the robustness analysis proposed by Oster (2015). The results showed that the BFP has an opposite effect to the one pronounced in the critiques of the program, the beneficiaries did not have more or fewer work hours than the non-beneficiaries, this fact can be explained by the value of the benefit not being able to meet the expenses of the household. From these results, we can conclude that both tests reinforce the importance of continuing the investigation of the effects on female labor supply in the rural environment in the light of different guidelines.
\end{abstract}

Keywords: Bolsa Família Program, labor participation, women, rural.

Resumo: Este artigo analisou o impacto do Programa Bolsa Família (PBF) sobre a oferta de trabalho das mulheres beneficiárias do PBF das áreas rurais no Brasil, com base nos dados da PNAD (2014), utilizando os métodos do propensity score matching (com os critérios nearest-neighbor, kernel e IPW) e mínimos quadrados ordinários no grupo de tratamento (beneficiárias) e controle (não beneficiárias) com análise de robustez proposta por Oster (2015). Os resultados apontaram que o PBF possui efeito contrário ao pronunciado nas críticas ao programa sobre a dependência das beneficiárias, pois essas mulheres não apresentaram menor ou maior jornada de trabalho do que as não beneficiárias. Esse fato pode ser explicado pelo valor do benefício não conseguir suprir as despesas do domicílio.

Palavras-chave: Programa Bolsa-Família, oferta de trabalho, mulheres, rural.

\section{INTRODUCTION}

In the 1990s, cash transfer programs in Brazil became part of government actions and were soon consolidated in the early 2000s after the unification of the first sectorial programs. Subsequently, there were changes in the criteria for selecting, granting, and coordinating benefits.

The conditional income transfer model emerged after the promulgation of the 1988 Federal Constitution, which implemented the concept of social security, which was incorporated definitively from 2003 with the creation of the Bolsa Família Program (Instituto de Pesquisa Econômica Aplicada, 2010). The Bolsa Família Program was created by Provisional Measure No. 132 , and subsequently became law by the number 10,836, of January 9,2004 , and regulated by Decree No. 5,209, of 2004 (Brasil, 2016). It is currently the main conditional cash transfer (CCT) program of the Federal Government.

The Bolsa Família Program (BFP) aims to eradicate poverty through the conditional cash transfer policy (CCTP). This kind of policy consists of transferring income to families that meet conditionality requirements, such as the school attendance of their children (in the BFP). 
Governments argue that the CCTP may represent a solution for the budgetary constraints faced by social policies by reducing the administrative resources spent on them.

The benefit granted by the BFP varies according to the income and composition of the family (poor or extremely poor). According to 2016 data from Brasil (2019), the government considers poor or extremely poor families composed of children up to fifteen years of age and/ or pregnant women, whose per capita monthly income is equal to or less than $R \$ 120.00$ and $R \$ 60.00$, respectively. Extremely poor families receive a fixed monthly stipend of $R \$ 58.00$, plus a variable addition of $R \$ 18.00$ per child enrolled in the program, for up to three children per family. As reported by data from the Ministry of Social and Agrarian Development, in 2016, the BFP benefited 13.9 million families with an average value of $\mathrm{R} \$ 182.03$.

Considering the social and economic levels of Brazil in recent years, these programs operate in a large part of the rural population. The rural scenario presents a higher percentage of poverty, low education, and, consequently, lower school attendance as historically evident aspects. Other factors also confirm that family composition is different between rural and urban areas. It is worth noting that, among all Brazilian women studied by Instituto Brasileiro de Geografia e Estatística (2014), (total sample of 394,819), 21.36\% are rural residents of the country. In this group, $29.60 \%$ have children and $31.75 \%$ have a paid job.

Most BFP beneficiary families live in rural areas and women are responsible for receiving the benefit and, often, deciding how to use it in family expenses. In rural areas, many women earn their living from their property, it is one of the main differences in the dynamics of work between rural and urban areas. According to data from the 2004 and 2014 PNADs, in 2004, the population of women in rural areas, aged from 16 to 65 and with a paid job, corresponded to $95.46 \%$ while in 2014 this same age group of women represented $43.42 \%$.

One of the most recurring criticisms of the performance of conditional cash transfer programs such as the BFP is the fear that the program will create dependency on the beneficiary families, for not generating jobs and paying an income (even if it is less than a minimum wage), which encourages family members not to work (Tavares, 2008).

This criticism sparked several debates in the literature on labor supply and conditional cash transfers. The offer of individual work can be understood from the Becker model (Becker, 1965), which studied the decision of how much time the family allocates to work, according to the family salary and non-work-related incomes, such as transfers of government incomes. With a positive shock of income resulting from a transfer, according to this model, we can have a change between the time directed to paid and unpaid activities within the home, in which the time allocated to paid work can be reduced compared to leisure and other activities. This is the so-called income effect, identified by Parker \& Skoufias (2000).

However, for this income transfer literature, additionally, to the income effect, there is a discussion about supposing the existence of a substitution effect, resulting from the imposition of conditionalities. The main requirement is that children attend classes to receive the benefit, so there must be a reduction of their work at home, which could be compensated by an increase in work offered by another family member. Therefore, the impact of the program on the job offer for beneficiaries is not conclusive because it depends on two effects (income and substitution), which work in opposite directions.

The allocation of family work time may still follow an intra-family division, and the decision on how time is spent on domestic activities and paid work may vary among members. So, cultural aspects are crucial for this variability of substitution in family activities.

Considering the relevance of the relationship between job offer and participation in the $\mathrm{BFP}$, in the problem of the study, the following question was raised: Does the Bolsa Família 
Program reduce the job offer of women in rural Brazil? To answer this question, this study has the general objective of analyzing the impact of the Bolsa Família Program on the labor supply for women, with an emphasis on rural areas in Brazil.

This study is also justified by the importance of evaluating income transfer programs and their effect on the economy of Brazilian regions, with an emphasis on aspects of the population in rural areas and women. Therefore, the main objective is to analyze the impact of the Bolsa Família Program on the labor supply for women in rural Brazil.

To develop the methodology, we used data from Instituto Brasileiro de Geografia e Estatística (2014), as they represent the recent changes in the economic scenario. The methodology was defined by the application of the Propensity Score Matching (PSM), a method suggested by the literature, to compare women benefiting from BFP with non-beneficiaries, constituting the treatment and control groups, respectively. To validate the PSM findings, we used other matching criteria. Therefore, with the pairing analysis, we expected to find some impact on the beneficiaries' working hours in rural Brazil with their participation in the program.

This work is organized into five sections, including the introduction. The second section presents the literature review with empirical international and national evidence on cash transfer programs. The third section describes the methodological procedures of this study. The fourth section highlights the results and their main discussions. And in the fifth section, we present the final considerations.

\section{CONDITIONAL CASH TRANSFER AND JOB SUPPLY PROGRAMS}

\subsection{International Evidence}

At the international level, Skoufias \& Di Maro (2006) studied the PROGRESA cash transfer program (currently known as Oportunidades) in Mexico and examined whether the program affected adult participation in the labor market and leisure time. In evaluating PROGRESA, the authors used the experimental design of the program and found that the program did not have any significant effect on the participation of the workforce and leisure time of adults, in contrast, the program leads to a substantial reduction of poverty in the country.

González \& Rivera (2008) studied the Apoyo Alimentario Program in southern Mexico and identified that the program has no impact on adult work participation, however, the results showed a negative impact on participation in agriculture and a positive effect on activities not related to agriculture.

Borraz \& González (2009) investigated the impact of conditional cash transfer programs on child labor and the job offer in the poorest households in Uruguay in the period from 2005 to 2007. The authors applied the propensity score matching estimation method to control the endogeneity of participation in the program. The results showed that the program has no impact on school attendance, but reduces the supply of female workers in the capital Montevideo, where more than $70 \%$ of the beneficiaries live. In addition, negative effects are detected in the labor market in other urban areas.

A recent study by Arau Pontones (2014) analyzed the impact of the Oportunidades cash transfer program in Mexico on the work of indigenous and non-indigenous people living in rural areas. Estimates of the average treatment effect suggest that the positive income shock created by the program does not affect work incentives for any of the rural participants. In these terms, the author confirms the rejection of the hypothesis that the program creates undesirable result for people who work less and become dependent on the program. 


\subsection{National Evidence}

Previous studies show the effects of BFP on the job offer of beneficiaries in Brazil and demonstrate the need to continue the discussion, as this program has changed many numbers in the Brazilian socioeconomic scenario in recent years. Therefore, this section presents national empirical evidence, based on the relationship between social programs and labor supply.

Ferro \& Nicollela (2007) estimated the effect of conditional transfers on the participation rate and hours worked by adults in urban and rural areas. The authors found a positive and significant effect only for men and women in urban areas but a negative effect on women in rural areas in Brazil.

Medeiros et al. (2007) analyzed the relationship between participation in the program and the job offer from PNAD 2004 data, using the probit model, and estimated that the job offer was positively affected by the BFP in groups of married women, male heads of the family and married men, but only female householders who receive the benefit are less likely to find a job than non-beneficiaries. And men do not have their job offer reduced (nor women who are not heads of the household). Following this assessment, adults whose family receives the benefit have a 3\% higher participation rate in the labor market than in non-beneficiary families.

The authors also showed the virtuous cycle that can be inherent in this process of income transfer, as transfers allow families to increase their consumption, or investment to supply demand. In these terms, transfers and investment can be linked. In addition, the authors observed that the labor market participation rate is higher among BFP beneficiaries (74.5\%) than among non-beneficiaries (68.3\%) and stated that there are still no robust results on the impact of the program on labor supply.

Tavares (2008) investigated the role of Bolsa Familia in the job offer of beneficiary mothers and found the existence of an income effect associated with the value of the benefit, but the work pointed out that the net effect of being a beneficiary of the program is positive (substitution effect), due to greater availability of time to work for them. That is, the substitution effect arises from the conditionalities because, with children and adolescents attending school, some other family members would have to compensate for the work previously done by them.

The author found that the impact on the decision of beneficiary mothers to work is reduced as the value of the transfer increases, although not considered in magnitude, and concluded that the higher the per capita income of a family, the lower their participation in the labor market and the greater the number of hours available will be. Thus, the 'substitution effect' will occur if the income effect is preponderant.

Teixeira (2010) studied the impact of BFP income on the labor market, separating beneficiary men and women and analyzing its effects, using PNAD 2006 data in addition to the model proposed by Becker (1965). A comparison was made between beneficiaries and non-beneficiaries who have the same characteristics, excluding the participation of the BFP. The results showed that there is no effect of the BFP on the likelihood of working for men or women and that the reduction in hours worked is not of great magnitude, as well as, the labor supply is elastic according to gender and the type of occupation.

Informality increases the effect on the supply of hours worked, and women are more sensitive to changes in income compared to men, as women contribute more to domestic production and parenting, which may change the supply of their work. In addition to the fact that women are responsible for receiving the benefit, which can influence decision making, by ensuring compliance with conditionalities (Teixeira, 2010).

Foguel \& Barros (2010) investigated the effects of the benefit on the labor supply of men and women, using the panel of municipalities included in the PNADs (2001-2005), and using an indirect method to identify the beneficiary families of the BFP. Costa et al. (2018), when studying the impact of the BFP on the supply of the rural population in Brazil, also found no significant effect of the policy on labor supply. 
Given the above, different results are noted regarding the impact of the BFP on the labor market, possibly explained by the use of different methodological techniques, and by analyzing different regions of Brazil. However, efforts to understand the dynamics of the workday on the performance of income transfer programs are evident, mainly because these last works did not specifically study the dynamics of women in rural areas when receiving the transfer of income.

\section{METHODOLOGY}

In this section, methodological procedures are inferred to measure the effects of the causal relationship between the job offer and participation in the BFP in rural areas. In this context, the mothers' working hours, represented by the weekly hours worked, are considered as a variable of interest, which may change due to participation in the BFP.

In order to measure the average effect of the program on labor supply, it is necessary to investigate the mothers who participate and those who do not participate in the BFP. Therefore, it is necessary to compare them regarding their participation in the program, in other words, we will use women who participated (treatment) and women who did not participate (control) in the BFP. This separation is justified by the impossibility of comparing the same woman in the situation of beneficiary and non-beneficiary because at a certain moment she will present one of the two situations.

One of the main criteria for comparing the two groups is related to the selection of the program. The selection for participation in a program is not always random, that is, it depends on two conditions: a) compose families registered in the Single Registry; and b) compose families corresponding to the criteria of income and family composition. Therefore, to select the sample, non-beneficiary women would need to meet the same criteria of income and family composition to be comparable to the group of beneficiaries (treatment).

However, to meet the main objective of the research and organize the treatment and control groups, the sample consisted of all women living in rural Brazil in 2014, aged over 18 and with a per capita family income lower or equivalent to 200 reais $^{1}$. Then, it is necessary to observe the characteristics of the sample that determine participation in the program and may be associated with the decision to work. For example, age, marital status, and place of residence. As for the locality, that the rural areas may have places that are difficult to access, making it impossible to register families.

In this context, the methodology used will control the non-randomness of the program. The literature indicates the use of the Propensity Score Matching method proposed by the authors Rosembaum \& Rubin (1983), for using data from a point in time, the year 2014, to find women not covered by the BFP and compare them to women who were, based on sociodemographic, geographic, occupational and household characteristics so that both groups present as the only potential difference the participation or not in the BFP. With that in mind, the next sections describe the data, descriptive statistics, and procedures used to demonstrate this methodology.

\subsection{Data and Descriptive Statistics}

We obtained the data used in this study from the National Household Sample Survey (PNAD) made annually by the Brazilian Institute of Geography and Statistics (IBGE) and referring to 2014. The choice for the year 2014 was motivated by providing identification of the families

\footnotetext{
These criteria were adopted so that our sample was composed of women with chances of participating in the income transfer program (BFP).
} 
that have access to the social policies ${ }^{2}$ of the Federal Government since in the present study we need to identify families benefited by the conditional cash transfer program, this database brought us a supplement with additional information about the access of families to the Single Registry of the Federal Government.

The sample consists of families residing in rural Brazil, in which women, female heads of family or wives are investigated, participating or not in the BFP, with per capita family income of $R \$ 0.00$ to $R \$ 200.00$ and family composition that meets the program requirements. To understand the main characteristics of the sample, PNADs annually provide information on several characteristics, including socioeconomic, occupational, demographic, and household characteristics.

Based on the sample, the variable of interest represents the hours worked between women benefiting from the program (treatment group) and non-beneficiary women (control group), given the observable characteristics of both groups.

The variables observed in this study were classified as: a) sociodemographic (variables indicating race, age, marital status, number of children, education); b) geographic (dummy variables indicating the regions of Brazil); c) household structure (dummy variables indicating piped water, garbage collection, sewage network and number of rooms per person).

Table 1 below presents the description of the variables used in this study to understand the descriptive statistics of women in rural areas in Brazil, considering the observable sociodemographic, geographical, occupational, and household structure characteristics based on the PNAD Instituto Brasileiro de Geografia e Estatística (2014).

Table 1 - Description of the variables

\begin{tabular}{lll} 
Characteristics & \multicolumn{1}{c}{ Variables } & \multicolumn{1}{c}{ Description } \\
Sociodemographic & White & Indicator - color /race white \\
& Black & Indicator - color /race black \\
& Pardo (base) & Indicator - color /race pardo \\
& Indigenous & Indicator - color /race indigenous \\
& Yellow & Indicator - color /race yellow \\
& Age (householder) & Indicator - age \\
& Education (householder) & Indicator - years of study (education) \\
& Children 0 - 7 years old & Indicator - number of children 0 - 7 years old \\
& Children 0 - 15 years old & Indicator - number of children 0 - 15 years old \\
& Single mother & Indicator - woman's marital status \\
& Northeast & Dummy Northeast region of Brazil \\
Southeast & Dummy Southeast region of Brazil \\
& Midwest & Dummy Midwest region of Brazil \\
& South & Dummy South region of Brazil \\
& North & Dummy North region of Brazil \\
& Formal employment & Indicator - Formal employment \\
Building activity & Indicator - Building Activity \\
Commerce activity & Indicator - Commerce Activity \\
& Service activity & Indicator - Service Activity \\
Agricultural activity (base) & Indicator - Agricultural Activity \\
\hline
\end{tabular}

Source: Based on data from Instituto Brasileiro de Geografia e Estatística (2014).

2 Information on CADUNICO, present in the Instituto Brasileiro de Geografia e Estatística (2014) supplement and information on other household income, was used to compose the sample of the present study. 


\subsection{Econometric Procedures}

This section presents the econometric procedures used to measure the effects of the BFP on the labor supply for Brazilian women living in rural areas. Initially, we divided the treatment and control groups.

The literature suggests the pairing of groups by the proposed Propensity Score Matching method to overcome the problem of selection bias through the average treatment effect on the treated (ATT). To validate the results of this matching, we applied the following methods: Nearest-neighbor matching (NN), Kernel matching, inverse probability weighting (IPW), and finally, ordinary least squares (OLS). To analyze the robustness of the OLS model, we used the Oster's robustness test (2015).

\subsubsection{Propensity Score Matching Method}

In assessing the impact of a social program, it is necessary to consider a possible selection bias. In this study, it is possible to find families benefiting from the BFP with more hours worked than non-beneficiary families under the same conditions. To get around the bias problem, we used the Propensity Score Matching (PSM) method.

In these circumstances, the individual $(I)$ is considered a woman in rural areas, a variable of interest $\left(\mathrm{Y}_{\mathrm{i}}\right)$ representing the job offer, and the comparison of these individuals based on the participation of the program: treated individuals (who participate in the program) and control individuals (who do not participate in the program).

One of the motivations for using the PSM pairing is the dimension of the vector $X$ of the observable characteristics as they are added, that is, with a larger base of characteristics, it increases the difficulty in finding the pairs, so Rosembaum \& Rubin (1983) suggested using a function of $X$ that summarizes all the information contained in the vector X. Accordingly, the PSM is defined as the probability of an individual participating in the program based on its characteristics, expressed in Equation 1 below:

$\mathrm{P}(\mathrm{X})=\operatorname{Pr}\left(\mathrm{BF}_{\mathrm{i}}=1 \mid \mathrm{X}\right)$

Where:

$\mathrm{P}(\mathrm{X})$ : Propensity score (the function of $\mathrm{X}$ ) with information from the vector of observable characteristics $X$.

$\operatorname{Pr}\left(\mathrm{BF}_{\mathrm{i}}=1 \mid \mathrm{X}\right)$ : probability of women in rural areas to participate in the $\mathrm{BFP}\left(\mathrm{BF}_{\mathrm{i}}\right)$ considering the set of observable characteristics $\mathrm{x}$.

In general, the PSM methodology comprises two hypotheses:

a) $\mathrm{H} 1$ : the selection of observable variables or ignorability. In this hypothesis, the result of a non-beneficiary woman is a good predictor of the potential result in the absence of participation in the BFP of a beneficiary mother who has the same vector $X$ (the same observable characteristics).

b) H2: overlapping hypothesis. Vector X must contain the characteristics of beneficiaries and non-beneficiaries. One of the recurring criticisms of this hypothesis is that if the unobservable characteristics are correlated with the decision to participate in the program and with the result of the woman being a beneficiary, pairing cannot eliminate the selection bias in estimating the average treatment effect on the treated (ATT).

In these terms, if $\mathrm{H} 1$ and $\mathrm{H} 2$ are valid and the probability is known, it is possible to estimate the ATT and pair beneficiaries and non-beneficiaries of the program based only on the PSM. 
Therefore, the literature recommends using parametric procedures to estimate probability in the first stage, in this case, the probit model.

To define the probability of participation in the BFP by women inserted in rural areas, it was necessary to estimate the probit model in the first stage, which estimates the impacts of the BFP on the working hours of wo. These effects are based on the following Equation 2:

$$
\begin{aligned}
& \mathrm{BF}_{\mathrm{i}}=\alpha+\beta_{1} \mathrm{X}_{\mathrm{is}}+\beta_{2} \mathrm{X}_{\mathrm{ig}}+\beta_{3} \mathrm{X}_{\mathrm{io}}+\beta_{4} \mathrm{X}_{\mathrm{id}}+\varepsilon_{\mathrm{i}} \\
& \mathrm{BF}_{\mathrm{i}}=1, \text { if } \varepsilon_{\mathrm{i}} \geq-\beta_{1} \mathrm{X}_{\mathrm{is}}-\beta_{2} \mathrm{X}_{\mathrm{ig}}-\beta_{3} \mathrm{X}_{\mathrm{io}}-\beta_{4} \mathrm{X}_{\mathrm{id}} \\
& \mathrm{BF}_{\mathrm{i}}=0, \text { otherwise. }
\end{aligned}
$$

Where:

$\mathrm{BF}_{\mathrm{i}}$ : Dummy variable indicating women in rural areas $i$ being a beneficiary of the BFP.

$\beta_{1}, \beta_{2}, \beta_{3}$ e $\beta_{4}$ : Parameter vectors.

$\mathrm{X}_{\mathrm{is}}$ : Sociodemographic characteristics vector.

$\mathrm{X}_{\mathrm{ig}}$ : Geographic characteristics vector.

$\mathrm{X}_{\mathrm{io}}$ : Occupational characteristics vector.

$\mathrm{X}_{\mathrm{id}}$ : Household general characteristics vector.

Based on these considerations, the first stage determines the regression estimation procedure to find the likelihood of a rural woman participate in the BFP $\left(\mathrm{BF}_{\mathrm{i}}=1\right)$, in the estimated probit model.

The second stage is defined by estimating the effects of BFP on the participation of women in the labor market. Matching based on the propensity score depends on a metric that defines the proximity of the probabilities between the beneficiary and non-beneficiary women. Becker \& Ichino (2002) suggest several ways to define this metric, and in this study, the main ones will be applied: nearest-neighbor and Kernel'3 in addition to IPW ${ }^{4}$.

Considering the assumption of conditional independence, we must check whether the pairing procedure has balanced the distributions of the observable variables between the control and treatment groups. According to Austin (2009), we should check the joint significance of the observable variables, after pairing the pseudo-R2 must be low, and in this case, the quality of the pairing is satisfactory. If the quality of the pairing is not satisfactory, the assumption of conditional independence has failed.

Then, OLS estimation was performed to find the variables that strengthen the pairing model between the treatment and control groups. To validate the OLS findings, the Oster robustness test procedures (2015), described in the next section, were implemented.

\subsubsection{Oster Robustness Test}

We used Oster's methodology (Oster, 2019) to perform the robustness test. This test consists of finding the degree of selection on the unobservable variables concerning the observables,

\footnotetext{
3 According to Becker \& Ichino (2002), the pairing by the nearest neighbor seeks to identify for each individual in the treated group a correspondent with similar observable characteristics in the control group, for this the technique uses the closest propensity score for the pairing. The kernel pairing method or technique, as well as the nearest-neighbor method, performs pairing between individuals with the closest propensity scores but assigns a weight to each control case inversely proportional to the distance of their peer from the treatment group.

4 The idea of weighting the inverse probability (IPW) is to build a pseudo-sample in which there are no imbalances in the covariates measured between the treatment groups.
} 
which may be sufficient to explain the lack of impact of the treatment, given the proportionality hypothesis, which seeks the degree of selection for a value very close to 1 , represented in this study by the letter $\delta$ (proportionality coefficient).

In other words, this methodology follows the notion proposed by Altonji et al. (2005), in which the unobservable variables should not be more significant than the observable variables in explaining the treatment.

Note that the vector of observable variables $\mathrm{X}$ is a random selection of the total set $(\mathrm{X}, \mathrm{U})$, then $\delta=1$. Oster (2019) argues that $\mathrm{X}$ usually contains the most important variables in explaining the treatment, so $\delta$ must be greater than 1 (the selection of unobservables must not exceed the selection of observables).

In this sense, it is possible to easily obtain estimates of the non-biased ATT by calculating the bias by $B(\delta)$. However, it is noted that calculating this number requires knowledge of the value of $R_{\max }$ that is not observed. Oster argues that there is some randomness in the movements of the control variable leading $R_{\max }$ to be less than 1 . In the estimates of this study, $R_{\max }$ values ranging from 0.7 to 0.9 (suggested by Oster's work) were considered to calculate $\delta$.

According to the approach adopted by Altonji et al. (2005) and Oster (2019), we can obtain the value of $\delta$, sufficient to explain the entire treatment effect, which would make $\hat{\beta}=0$. This number refers to the degrees of selection in the unobservable variables concerning the observables, which would be required by the treatment to be fully explained by the unobservables, not included in the model.

With the application of the methodology, the following section presents the results found of the causal relationship between labor supply and fertility for the beneficiaries of the BFP.

\section{RESULTS AND DISCUSSION}

This section presents the results of the main question of this study, in other words, about whether participating in the BFP affects the labor supply of Brazilian women living in rural areas. Therefore, the estimates of the effects in two stages are presented.

Table 2 below shows the main descriptive statistics for the variables that we used in the first stage of the PSM model, where the chances of a woman being a beneficiary of the BFP are estimated, which in a second stage will allow us to observe the difference in the average between beneficiaries or not of the program with respect to the job offer. We formulated Table 2 considering the criteria to be eligible in the program, income (not exceeding $R \$ 200$ monthly), and family composition, to understand the descriptive statistics of rural women in Brazil. It is clear that before pairing we already expected that there would be a difference in the average between the control group and the treatment group since there was no draw to select the women covered by the policy. However, after matching, we did not observe differences in means for observable characteristics between Treatment and Control.

The sample was grouped according to the participation of the BFP, with a sample size of 1649 observations for women beneficiaries of the BFP and 7699 observations for women nonbeneficiaries of the program.

Based on the descriptive statistics presented, there are variables to be used in the pairing between the beneficiary and non-beneficiary groups of the program, that is, factors that affect the chance of a family being eligible for the BFP. It is also noted that there is a significant difference between the two groups (treatment and control), before pairing. However, it can also be seen in Table 2 that there is no relevant difference in average between groups after matching. 
Table 2 - Descriptive Statistics of Non-Beneficiaries and Beneficiaries of BFP in Rural Brazil

\begin{tabular}{|c|c|c|c|c|c|c|}
\hline \multirow{3}{*}{$\begin{array}{l}\text { Sociodemographic } \\
\text { Characteristics }\end{array}$} & \multicolumn{3}{|c|}{ Unpaired } & \multicolumn{3}{|c|}{ Paired } \\
\hline & Treated & Control & \multirow{2}{*}{ Difference } & Treated & Control & \multirow{2}{*}{ Difference } \\
\hline & Average & Average & & Average & Average & \\
\hline $\begin{array}{l}\text { Children } 0 \text { - } 15 \\
\text { years old }\end{array}$ & 1.96 & 1.59 & $0.37 *$ & 1.96 & 1.94 & $0.02^{\mathrm{NS}}$ \\
\hline Age (householder) & 36.6 & 35.92 & $0.69^{\mathrm{NS}}$ & 36.61 & 36.49 & $0.12^{\mathrm{NS}}$ \\
\hline Color or race (white) & 0.18 & 0.21 & $-0.03^{*}$ & 0.18 & 0.19 & $-0.01^{\mathrm{NS}}$ \\
\hline $\begin{array}{l}\text { Color or race } \\
\text { (pardo) }\end{array}$ & 0.66 & 0.65 & $0.01^{\mathrm{NS}}$ & 0.65 & 0.65 & $0.00^{\mathrm{NS}}$ \\
\hline $\begin{array}{l}\text { Color or race } \\
\text { (yellow) }\end{array}$ & 0.00 & 0.00 & $0.00^{\mathrm{NS}}$ & 0.00 & 0.00 & $0.00^{\mathrm{NS}}$ \\
\hline $\begin{array}{l}\text { Color or race } \\
\text { (indigenous) }\end{array}$ & 0.05 & 0.03 & $0.02^{\mathrm{NS}}$ & 0.05 & 0.03 & $0.02^{\mathrm{NS}}$ \\
\hline Color or race (black) & 0.08 & 0.09 & $-0.01^{\mathrm{NS}}$ & 0.08 & 0.09 & $-0.01^{\mathrm{NS}}$ \\
\hline Years of study & 4.43 & 5.72 & $-1.29 *$ & 4.43 & 4.55 & $-0.12^{\mathrm{NS}}$ \\
\hline Single mother & 0.50 & 0.416 & $0.085^{*}$ & 0.501 & 0.518 & $-0.01^{\mathrm{NS}}$ \\
\hline \multicolumn{7}{|l|}{ Occupational } \\
\hline Formal employment & 0.006 & 0.023 & $-0.017^{*}$ & 0.006 & 0.004 & $0.002^{\mathrm{NS}}$ \\
\hline Building activity & 0.001 & 0.001 & $0.00^{\mathrm{NS}}$ & 0.001 & 0.001 & $0.00^{\mathrm{NS}}$ \\
\hline Commerce activity & 0.019 & 0.021 & $-0.002^{\mathrm{NS}}$ & 0.019 & 0.017 & $0.002^{\mathrm{NS}}$ \\
\hline Service activity & 0.43 & 0.57 & $-0.14^{*}$ & 0.43 & 0.437 & $-0.007^{\mathrm{NS}}$ \\
\hline \multicolumn{7}{|l|}{ Geographic } \\
\hline South & 0.02 & 0.05 & $-0.03^{*}$ & 0.02 & 0.03 & $-0.006^{\mathrm{NS}}$ \\
\hline Midwest & 0.04 & 0.04 & $0.00^{\mathrm{NS}}$ & 0.04 & 0.02 & $0.02^{\mathrm{NS}}$ \\
\hline Northeast & 0.68 & 0.51 & $0.16^{*}$ & 0.68 & 0.70 & $-0.02^{\mathrm{NS}}$ \\
\hline North & 0.23 & 0.29 & $-0.06 *$ & 0.20 & 0.20 & $0.02^{\mathrm{NS}}$ \\
\hline Southeast & 0.04 & 0.11 & $-0.06 *$ & 0.046 & 0.04 & $0.00^{\mathrm{NS}}$ \\
\hline Observations & 1649 & 7699 & & 1649 & & \\
\hline
\end{tabular}

In Table A1 (Annex), we have the first stage of PSM. In this case, we estimate the chances of a woman belonging to the treatment group. The variables with the highest correlation with participation in the program are the number of children under the age of 15 , education (the lower the number of years of schooling for a woman, the lower the chance of being a beneficiary), formal employment, and the Midwest region that contribute also negatively with participation in the BFP.

Table 3 contains statistics that summarize the quality of the PSM implementation. The second column of Table 3, the pseudo-R2, obtained from the estimation of the probability of conditional treatment (propensity score) in both samples (paired and unpaired), shows that the model has significantly less power to explain the status of the treatment after pairing. This is complemented by the Likelihood Ratio (LR) test of the joint insignificance of all regressors in column 3, which 
also suggests that the paired sample is well balanced in the observed variables. In addition, a substantial reduction in the mean and median of the absolute bias (difference in the means and medians of the covariates before and after matching, for control versus treatment), as calculated in Rosenbaum \& Rubin (1985), are presented in columns 5 and 6.

Table 3 - Balancing the PSM

\begin{tabular}{lrrrrc}
\multicolumn{1}{c}{ Sample } & Ps $\mathbf{R}^{2}$ & LR X & p $\mathbf{C h}^{2} \mathbf{2}$ & Bias Mean & Bias Median \\
Unpaired & 0.069 & 207.68 & 0.00 & 21.1 & 14.6 \\
Paired & 0.002 & 4.43 & 0.99 & 7.4 & 6.8 \\
\hline
\end{tabular}

Source: Based on Instituto Brasileiro de Geografia e Estatística (2014) data. Note: Ps - Pseudo R²

After matching or identifying a control group as close as possible, in terms of observable characteristics to the treatment group, we performed the difference in a mean or the estimate of the average effect of the treatment (Bolsa Família) on the hours worked by the methods: ordinary least squares (OLS), nearest-neighbor, Kernel, and IPW. Table 4 below shows the results of applying the OLS, NN, Kernel, and IPW methods.

Table 4 - Average Treatment Effect on Worked Hours

\begin{tabular}{cccccc} 
& Obs. & N. Treated & N. Control & ATT & SE \\
OLS & 2494 & - & - & $0.98^{\mathrm{NS}}$ & 0.620 \\
NN & 1258 & 730 & 528 & $1.16^{\mathrm{NS}}$ & 1.205 \\
Kernel & 2506 & 731 & 1775 & $1.64^{\mathrm{NS}}$ & 0.902 \\
IPW & 2494 & - & - & $0.89^{\mathrm{NS}}$ & 0.670 \\
\hline
\end{tabular}

Source: Based on Instituto Brasileiro de Geografia e Estatística (2014) data. Note: ${ }^{*} p$-value $<0.01 .{ }^{* *} p$-value $<0.05$. NS is not significant. SE: Standard error. NN: Nearest neighbor. The variables used as a control in the linear regression model (OLS) are the same as shown in Table 1.

The average effect of BFP on hours worked indicates on average how much women in the treatment group work compared to women in the control group, the estimation of these effects, based on different criteria, are shown in Table 4. Considering the result of the nearest-neighbor method 'NN', the average effect of the BFP on the working hours of women in rural areas was not significant, that is, on average, beneficiaries of the program do not have more or fewer hours worked than the non-beneficiaries. This result can also be observed when we use other strategies to estimate the average effect of treatment. Based on the application of OLS and IPW (with a significance of 1\%), the results confirm that the beneficiaries do not have more or fewer working hours than the non-beneficiaries.

By raising income, families can be encouraged to have more leisure time (not work) and reduce their participation in the workforce or their number of hours worked, even among women from families with lower incomes. However, the evidence from studies evaluating conditional cash transfer programs suggests that most of this kind of policy does not create a disincentive for paid work. Both evidence for the urban environment Foguel \& Barros (2010), Skoufias \& Di Maro (2006), Teixeira (2010) and for the rural environment and the studies by Tavares (2008), Arau Pontones (2014), and Costa et al. (2018), showed no effect of income transfer programs on labor supply. The results of these previous works are similar to the ones we found in this study, however, our concern was the rural environment of Brazil, with a focus on the female workforce. 
Table 5 - Average Treatment Effect on hours worked by region of Brazil

\begin{tabular}{lcc} 
& Northeast & ATT \\
\cline { 2 - 3 } Nearest neighbor & Obs. & $-0.144^{\mathrm{NS}}$ \\
Kernel & 862 & $1.93^{\mathrm{NS}}$ \\
IPW & 1411 & $1.98^{\mathrm{NS}}$ \\
\hline & 1411 & \\
Nearest neighbor & Southeast & $1.19^{\mathrm{NS}}$ \\
Kernel & 59 & $1.15^{\mathrm{NS}}$ \\
IPW & 211 & $8.64^{\mathrm{NS}}$ \\
\hline Nearest neighbor & 211 & $10.60^{\mathrm{NS}}$ \\
Kernel & South & $4.24^{\mathrm{NS}}$ \\
IPW & 43 & $8.62^{\mathrm{NS}}$ \\
\hline & 106 & \\
Nearest neighbor & 106 & $2.38^{\mathrm{NS}}$ \\
Kernel & North & $1.90^{\mathrm{NS}}$ \\
IPW & 311 & $4.37^{*}$ \\
Nearest neighbor & 704 & $7.55^{\mathrm{NS}}$ \\
Kernel & 704 & $2.64^{\mathrm{NS}}$ \\
IPW & Midwest & $9.96^{\mathrm{NS}}$ \\
\hline
\end{tabular}

Source: Based on Instituto Brasileiro de Geografia e Estatística (2014) data. Note: *p-value<0.01. ${ }_{* *}$ p-valuer $<0.05 . * * *$ p-value $<0.10$. NS is not significant

In Table 5, we estimate the effect of the BFP on the labor supply for each of the regions of Brazil. The results have not changed, compared to those obtained for Brazil as a whole. In other words, receiving the benefit does not seem to alter the paid work routine of rural women.

To test the robustness of these results, the Oster (2019) procedure was used to obtain limits for the parameter of interest and selection values on the unobservable variables, which would be needed when comparing with the observable ones to fully explain the estimates, in other words, to control only for observable variables.

Table 6 shows the ATT tending to zero for each increase in the value of $\mathrm{R}_{\max }$. For the first estimation we have the $R_{\max }$ with the value of 0.7 and delta with the value of 4.78960 , that is, it would be necessary for the effect of unobservable characteristics to be 4.789 stronger than the effect of observable features.

As the $\mathrm{R}_{\max }$ increases, the strength of the effect of unobservable features decreases to explain the entire negative effect. If the delta value is greater than 1 , we will need strength in the effect of the observable characteristics. In this case, the farther the delta is from 1, the less chance of having unobservable factors that may explain the observed effect.

Table 6 - Oster Robustness Analysis

\begin{tabular}{cccc}
\multirow{2}{*}{ Parameter } & \multicolumn{3}{c}{$\mathrm{R}_{\max }$} \\
\cline { 2 - 4 } & $\mathbf{0 . 7}$ & $\mathbf{0 . 8}$ & $\mathbf{0 . 9}$ \\
$\delta$ to $\beta=0$ & 4.78960 & 2.83862 & 2.01702 \\
Identification $(\mathrm{a}=1)$ & {$[1.133282 ; 0.85224]$} & {$[1.13282 ; 0.85224]$} & {$[1.13282 ; 0.85224]$} \\
\hline
\end{tabular}




\section{CONCLUSIONS}

This work analyzed the impact of the Bolsa Família Program on the labor supply of women in rural Brazil based on PNAD data (2014), using the PSM (with the nearest neighbor, Kernel Matching and IPW criteria) and Minimum Ordinary Squares methods, applying the robustness analysis proposed by Oster (2019). The robustness approach proposed by Oster (2019) indicated that the results of hours worked on the participation of the BFP are robust in the analysis of the variable hours worked. That is, this program has had no impact on the workday, considering women in rural Brazil. Therefore, the results suggest that the beneficiaries under the program do not have a shorter working day compared to those who are not beneficiaries of the Program, for 2014.

This work estimated a treatment effect through the pairing between the treatment (beneficiary women) and control (non-beneficiary women) groups regarding the participation of the program, to find the existence of the 'laziness effect' or 'substitution effect', in rural areas from the 2014 data. The results showed reports similar to those found in the literature for the urban environment of Brazil, that is, the Bolsa Família Program does not generate dependence on the beneficiaries, who had a similar workday when compared to women not covered by the program.

Consequently, we should note that the analysis covered one year, but it is valid to compare the results of the methods applied with the urban environment or in the rural and urban population of Brazil together, considering a greater time cut to accompany the development of this impact on rural areas, because of the scarcity of studies that address these areas, which consists of important aspects for future investigations.

\section{REFERENCES}

Altonji, J. G., Elder, T. E., \& Taber, C. R. (2005). Selection on observed and unobserved variables: assessing the effectiveness of catholic schools. Journal of Political Economy, 113(1), 151-184. Retrieved in 2020, September 22, from www.jstor.org/stable/10.1086/426036

Arau Pontones, J. (2014). The effects of conditional cash transfers on work incentives of the Mexican rural population: does oportunidades create income dependency? (Master's thesis). Lund University, Lund.

Austin, P. C. (2009). Balance diagnostics for comparing the distribution of baseline covariates between treatment groups in propensity-score matched samples. Statistics in Medicine, 28(25), 3083-3107.

Becker, G. S. (1965). A Theory of the Allocation of Time. Economic Journal (London), 75, 493517. [Reprinted in Becker (1976])

Becker, S., \& Ichino, A. (2002). Estimation of average treatment effects based on propensity scores. The Stata Journal, 2(4), 358-377.

Borraz, F., \& González, N. (2009). Impact of the Uruguayan conditional cash transfer program. Cuadernos de Economía (Santiago, Chile), 46(134), 243-271.

Brasil. Ministério do Desenvolvimento Social e Combate à Fome. (2016). Efeitos do Programa Bolsa Família na redução da pobreza e distribuição de renda. Retrieved in 2016, September 8, from http://www.ipc-undp.org/publications/mds/46P.pdf

Costa, R. A., Costa, E. M., Mariano, F. Z., \& Cavalcanti, D. M. (2018). Impactos do Programa Bolsa Família no mercado de trabalho e na renda dos trabalhadores rurais. Nova Economia, 28(2), 385-416. 
Ferro, A., \& Nicollela, A. (2007). The impact of conditional cash transfer programs on household work decisions in Brazil. São Paulo: Universidade de São Paulo. Mimeografado.

Foguel, M., \& Barros, R. (2010). The effects of conditional cash transfer programmes on adult labour supply: an empirical analysis using a time-series-cross-section sample of Brazilian municipalities. Estudos Econômicos (São Paulo), 40(2), 259-293.

González, T. \& Rivera, J. (2008). Nutrición y Pobreza. Política pública basada en evidencia. Ciudad de México: Banco Mundial - sedesol.

Instituto Brasileiro de Geografia e Estatística - IBGE (2014). Pesquisa Nacional de Amostra por Domicílio - PNAD. Retrieved in 2015, August 5, from: https://www.ibge.gov.br/estatisticas/ sociais/rendimento-despesa-e-consumo/9127-pesquisa-nacional-por-amostra-de-domicilios. html.

Instituto Brasileiro de Geografia e Estatistica - IBGE. (2016). Retrieved in 2016, August 1, from www.ibge.gov.br

Instituto de Pesquisa Econômica Aplicada - IPEA. (2010). Bolsa Família 2003-2010: avanços e desafios. Brasília: IPEA.

Medeiros, M., Britto, T., \& Soares, F. (2007). Transferência de renda no Brasil. Novos Estudos CEBRAP, (79), 5-21. http://dx.doi.org/10.1590/S0101-33002007000300001.

Brasil. Ministério da Cidadania. (2019). Retrieved in 2019, December 1, from http://mds.gov. br/assuntos/bolsa-familia/gestao-do-programa/condicionalidades.

Oster, E. (2019). Unobservable selection and coefficient stability: theory and evidence. Journal of Business \& Economic Statistics, 37(2), 187-204.

Parker, S., \& Skoufias, E. (2000). The Impact of Progresa on Work, Leisure and Time Allocation (IFPRI Final Report on Progresa). Washington, DC: IFPRI.

Rosembaum, R., \& Rubin, B. (1983). The central role of the propensity score in observational studies for casual effects. Biometrika, 70, 41-55.

Rosenbaum, P., \& Rubin, D. (1985). Constructing a Control Group Using Multivariate Matched Sampling Methods That Incorporate the Propensity Score. The American Statistician, 39(1), 33-38. http://dx.doi.org/10.2307/2683903

Skoufias, E., \& Di Maro, V. (2006). Condition cash transfers, adult work incentives and poverty. The Journal of Development Studies, 44(7), 935-960.

Tavares, P. (2008). Efeito do programa Bolsa Família sobre a oferta de trabalho das mães. In Anais do $36^{\circ}$ Encontro Nacional de Economia. Salvador, BA: ANPE.

Teixeira, C. G. (2010). Análise da heterogeneidade do programa Bolsa Família na oferta de trabalho dos homens e das mulheres. Bolsa Família 2003-2010: avanços e desafios (Vol. 2, pp. 89-109). Brasília: IPEA. 


\section{Annex}

Table A1: First Stage of Propensity Score Matching, dependent variable Bolsa Família

\begin{tabular}{|c|c|c|}
\hline Variables & Coefficients & Standard Error \\
\hline Children 0 - 7 years old & $0.03^{\mathrm{NS}}$ & $(0.039)$ \\
\hline Children $0-15$ years old & $0.068 * * *$ & $(0.021)$ \\
\hline Age (householder) & $-0.003^{\mathrm{NS}}$ & $(0.002)$ \\
\hline White (color/race) & $-0.024^{\mathrm{NS}}$ & $(0.072)$ \\
\hline Black (color/race) & $-0.060^{\mathrm{NS}}$ & $(0.097)$ \\
\hline Yellow (color/race) & $-0.157^{\mathrm{NS}}$ & $(0.483)$ \\
\hline Indigenous (color/race) & $-0.00^{\mathrm{NS}}$ & $(0.001)$ \\
\hline Years of study & $-0.048 * * *$ & $(0.008)$ \\
\hline Single & $-0.104^{\mathrm{NS}}$ & $0.081)$ \\
\hline Formal employment & $-0.465 *$ & $(0.260)$ \\
\hline Building Activity (work) & $0.037^{\mathrm{NS}}$ & $(0.657)$ \\
\hline Commerce Activity (work) & $-0.159^{\mathrm{NS}}$ & $(0.203)$ \\
\hline Service Activity (work) & $-0.391 * * *$ & $(0.082)$ \\
\hline South & $-0.099^{\mathrm{NS}}$ & $(0.162)$ \\
\hline Midwest & $-0.869 * * *$ & $(0.278)$ \\
\hline Northeast & $0.384 * * *$ & $(0.064)$ \\
\hline Southeast & $-0.222^{\star}$ & $(0.121)$ \\
\hline Constant & $-0.243^{\mathrm{NS}}$ & $(0.155)$ \\
\hline Observations & 2.494 & \\
\hline
\end{tabular}

Source: Pesquisa Nacional de Amostra por Domicílio (2014), ${ }^{* * *} p<0.01,{ }^{* *} p<0.05,{ }^{*} p<0.1$. NS is Not Significant 